\title{
Tecnologias Assistivas para Pessoas com Deficiência Visual
}

\author{
Assistive Technologies for People with Visual Disabilities
}

\author{
Adriana Monteiro da Cunha ${ }^{1}$ \\ Sidnei Cerqueira dos Santos ${ }^{1}$ \\ ${ }^{1}$ Universidade Federal do Sul e Sudeste do Pará, Marabá, PA, Brasil
}

\begin{abstract}
Resumo
O debate envolvendo acessibilidade e inclusão tem ampliado o foco sobre a necessidade de assegurar o amplo acesso aos direitos e aos serviços a pessoas com deficiência. As soluções para enfrentar os diversos desafios da área são específicas, uma vez que cada pessoa traz consigo singularidades relacionadas à sua deficiência. O desenvolvimento de tecnologias tem sido uma das aliadas para reduzir a lacuna existente para esse público. O objetivo deste trabalho foi realizar uma análise tecnológica de produtos de acessibilidade para pessoas com deficiência visual. A pesquisa de patentes foi realizada no Instituto Nacional da Propriedade Industrial (INPI) e no Escritório Europeu de Patentes (Espacenet $\left.{ }^{\circledR}\right)$, e a de programas de computador no INPI. Os resultados mostram que há possibilidades de mercado para o desenvolvimento de produtos tecnológicos para atender às necessidades de pessoas com deficiência visual, como a audiodescrição.
\end{abstract}

Palavras-chave: Acessibilidade. Cego. Baixa Visão.

\begin{abstract}
The debate involving accessibility and inclusion has broadened the focus on the need to ensure broad access to rights and services for people with disabilities. The solutions to face the different challenges in the area are specific, since each person brings with them singularities related to their disability. The development of technologies has been one of the allies to reduce the gap that exists for this audience. The aim of this work was to carry out a technological analysis of accessibility products for people with visual impairments. The patent search was carried out at the National Institute of Industrial Property (INPI) and European Patent Office (Espacenet $\left.{ }^{\circledR}\right)$, and of computer programs at INPI. The results show that there are great market possibilities for the development of technological products to meet the needs of people with visual impairments, such as audio description.
\end{abstract}

Keywords: Accessibility. Blind. Low Vision.

Área Tecnológica: Prospecção Tecnológica. Tecnologia e Inovação. 


\section{Introdução}

A visão é um dos mais importantes sentidos do indivíduo para o seu desenvolvimento social e cognitivo. Sem esta, a capacidade de interação e de comunicação é diretamente afetada, ocasionando uma série de limitações de atividades e de participação social, além da necessidade de adaptação ao ambiente onde a pessoa vive (NUNES; LOMÔNACO, 2008). De acordo com Oliveira e Neto (2019), a falta de acessibilidade às ferramentas da internet é um dos fatores limitantes no dia a dia dos usuários com deficiência visual.

A Organização Mundial de Saúde (OMS, 2003) classifica a deficiência visual em categorias, que vão desde a perda visual leve até a ausência total de visão, a partir de valores qualitativos de acuidade visual e/ou do campo visual para definir a cegueira e a baixa visão. Ainda de acordo com a OMS (2019), 2,2 bilhões de pessoas foram clinicamente diagnosticadas com deficiência visual em todo o mundo, representando cerca de $28 \%$ da população mundial. Desse percentual, também constam indivíduos com baixa visão, cegueira unilateral, entre outras doenças associadas a essa deficiência.

Dados do Instituto Brasileiro de Geografia e Estatística (IBGE, 2010) indicam que 6,2\% da população brasileira têm algum tipo de deficiência, como a auditiva, a visual, a física e a intelectual. Dessas deficiências, a visual é a mais expressiva, alcançando cerca de 3,6\% dos brasileiros, sendo que indivíduos com idade acima de 60 anos $(11,5 \%)$ estão na faixa de maior incidência. Dependendo da intensidade da limitação visual, $16 \%$ das pessoas com deficiência têm dificuldade ou estão impossibilitadas de realizar atividades de rotina, como trabalhar, ir à escola e manter hábitos de consumo (VILLELA, 2015). A Tabela 1 mostra o número e a porcentagem de pessoas com deficiência visual por regiões brasileiras.

Tabela 1 - Pessoas com deficiência visual por região no Brasil

\begin{tabular}{ccc} 
REGIÃo & Total & PopUlaÇão LOCAL (\%) \\
Norte & 574.823 & 3,6 \\
Nordeste & 2.192 .455 & 4,1 \\
Sudeste & 2.508 .587 & 3,1 \\
Sul & 866.086 & 3,2 \\
Centro-Oeste & 443.357 & 3,2 \\
\hline
\end{tabular}

Fonte: Adaptada do IBGE (2010)

Em dezembro de 2006, a Convenção sobre os Direitos das Pessoas com Deficiência, adotada em reunião da Assembleia Geral da Organização das Nações Unidas (ONU), reafirmou a universalidade, a indivisibilidade, a interdependência e a inter-relação de todos os direitos humanos e liberdades fundamentais, bem como a necessidade de que todas as pessoas com deficiência tenham a garantia de poder desfrutar plenamente desses direitos, sem discriminação. A Convenção também incorporou princípios e obrigações aos Estados-Partes, buscando assegurar e promover a plena realização de todos os direitos humanos (BRASIL, 2009). 
Manduchi, Kurniawan e Bagherinia (2013) destacam que muitas das informações apreendidas por nosso cérebro são diretamente municiadas pela visão. Com isso, cegos ou pessoas com baixa visão se deparam diariamente com restrições ou situações limitantes para executar as atividades cotidianas (OLOFSSON, 2017). Além da deficiência em si, as limitações também são determinadas pelo ambiente físico (e.g. acessibilidade) e social (e.g. preconceito, marginalização social), as quais essa parcela da população se enquadra, conforme apontado em Brasil (2009).

De modo geral, a acessibilidade promove condições de integração social e melhora a qualidade de vida das pessoas com deficiência, permitindo que elas possam interagir com o ambiente que as cerca de maneira autossuficiente, como definido por Sassaki (2009, p. 1-2), "[...] sem preconceitos, estigmas, estereótipo e discriminações, como resultado de programas e práticas de sensibilização e de conscientização das pessoas em geral e da convivência na diversidade humana".

Nesse sentido, novas tecnologias somadas às políticas públicas voltadas para a acessibilidade e inclusão têm permitido o desenvolvimento da tecnologia assistiva, como a audiodescrição, na qual estão inseridos os dispositivos, os equipamentos e os sistemas que visam a superar as dificuldades existentes na atualidade e que permitem não apenas uma relação mais igualitária junto à sociedade, como também oferecem maior qualidade de vida a esses indivíduos (HERSH; JOHNSON, 2010).

Inserida no campo da tradução audiovisual intersemiótica, a audiodescrição é uma ferramenta tecnológica que transforma o signo visual em verbal, permitindo a compreensão integral da narrativa audiovisual pelas pessoas com deficiência ou, ainda, por pessoas analfabetas, com dislexia ou com deficiência intelectual, abrindo possibilidades para maior acesso à cultura e à informação, contribuindo para a inclusão cultural, social e escolar (MIDIACE, 2020; MOTTA; ROMEU FILHO, 2010).

As tecnologias assistivas, como a audiodescrição, são geralmente protegidas na forma de patente e de programa de computador. Os documentos de patente apresentam os três pilares da inovação: novidade, atividade inventiva e aplicação industrial do produto a ser protegido (INPI, 2020). A prospecção tecnológica de patentes e de programas de computador é um importante recurso para identificação de tendências tecnológicas de mercado, como estágio de maturidade e tecnologias concorrentes, lacunas a serem preenchidas (INPI, 2020; RIBEIRO, 2018). Dessa forma, a empresa pode se antecipar às inovações e às mudanças no mercado (e.g. produtos de audiodescrição), podendo identificar oportunidades ou ameaças, criar estratégias para lidar com os impactos e desenvolver inovações antes dos competidores (RIBEIRO, 2018). O objetivo deste trabalho foi realizar uma análise tecnológica de produtos de acessibilidade para pessoas com deficiência visual.

\section{Metodologia}

A busca de documentos de patente foi realizada nas plataformas do Instituto Nacional da Propriedade Intelectual (INPI) e do Escritório Europeu de Patentes (Espacenet $\left.{ }^{\circledR}\right)$, e a de programas de computador no INPI. A pesquisa avançada de patentes foi realizada com palavras-chave: 
"acessibilidade" (accessibility), "audiodescrição" (audio description), "pessoa com deficiência" (disabled person), "cegos" (blind), "embalagem" (label), "leitor" (reader) e "rótulo" (packing), tanto no título quanto no resumo, associadas com código da Classificação Internacional de Patentes (CIP): G09B21/00, que trata de aparelhos para ensinar ou para comunicação voltados para cegos ou com deficiência visual, surdos ou mudos (Tabela 2). O operador booleano (AND) e o operador de truncagem (*) foram utilizados na busca com o objetivo de encontrar possíveis derivações das palavras selecionadas.

Tabela 2 - Escopo de busca

\begin{tabular}{ccc} 
Palavras-Chave & \multicolumn{2}{c}{ Bases De PATENTE } \\
\cline { 2 - 3 } Accessibility* + Audio description + Label & INPI & Espacenet \\
Audio description + Blind + Label & 1 & 6 \\
Audio description + Blind + Packing & 2 & 1 \\
Disabled person* + Blind + G09B21/00 & 1 & 1 \\
Disabled person* + Blind + Packing & 4 & 40 \\
Blind + Packing + Reader & 6 & 23 \\
Total & 6 & 41 \\
\hline
\end{tabular}

Fonte: Elaborada pelos autores deste artigo (2020)

A pesquisa por programa de computador utilizou as mesmas palavras-chave da pesquisa por patentes. A busca por patentes e programas de computador foi feita no período de publicação de 2000 a 2020, que corresponde ao desenvolvimento de tecnologias mais recentes (QUINTELLA; MATA; LIMA, 2019), considerando o período de sigilo de 18 meses das patentes (BRASIL, 1996). Um total de 91 (Tabela 2) patentes e 33 programas de computador foram selecionados para análise de aderência ao tema da pesquisa, retirando os documentos repetidos ou que não faziam parte do objeto da pesquisa. As inovações promissoras e com grande potencial de mercado foram apresentadas detalhadamente. Os resultados foram apresentados na forma de gráficos demonstrativos e de quadros, que evidenciaram o cenário e o desenvolvimento de tecnologias na área de produtos de acessibilidade para pessoas com deficiência visual.

\section{Resultados e Discussão}

Após a mineralização dos dados, foram selecionadas 14 patentes, sendo oito no Espacenet e seis no INPI, e mais 33 programas de computador (INPI), totalizando 47 inovações. A Figura 1 apresenta o número de patentes e de programas de computador a partir do recorte dos países de origem, com destaque para Estados Unidos e Japão. Grande parte dessas iniciativas é destinada ao acesso à educação, à cultura ou a serviços em geral, garantindo a pessoas com deficiência visual direitos previstos em lei (BRASIL, 1988) e estabelecidos em acordos internacionais entre nações (ONU, 2006), voltados para a inclusão e a acessibilidade. 
Figura 1 - Países com maior número de registros de patentes e programas de computador

17

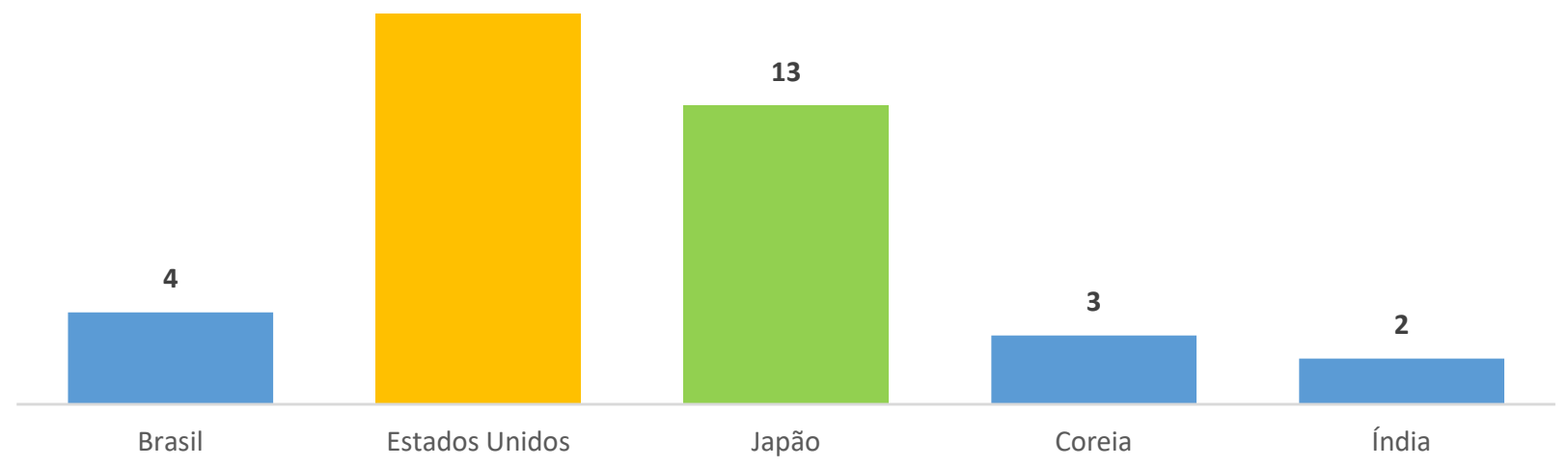

Fonte: Elaborada pelos autores deste artigo (2020)

Quanto aos depositantes, observa-se uma predominância de empresas da área de informática, com destaque para IBM (empresa americana), NEC e Sony (empresas multinacionais japonesa), além de outras organizações que oferecem soluções em telecomunicações (VENTURA, 2019), sobretudo para disponibilizar recursos e ferramentas para a interação das pessoas com deficiência no ambiente on-line.

No cenário brasileiro, as Instituições de Ensino Superior (IES) apresentaram quatro registros identificados no INPI, seguindo o perfil das tecnologias desenvolvidas em outros países, demonstrando a participação das IES brasileiras no desenvolvimento de produtos voltados para a acessibilidade, com foco em audiodescrição, descrição via áudio e/ou tecnologia assistiva (FRANCO, 2010). A Política Nacional para a Integração da Pessoa Portadora de Deficiência prevê que o ambiente universitário esteja adequado às pessoas com deficiência, estabelecendo, ainda, a adoção de planos e de núcleos de acessibilidade, fator este que favoreceu a produção de pesquisas e de soluções tecnológicas para atender à comunidade docente com algum tipo de deficiência (BRASIL, 1999).

Grupos de pesquisa estabelecidos dentro da academia têm importante papel nas discussões acerca da acessibilidade visual, com destaque para o grupo Tradução, Mídia e Audiodescrição da Universidade Federal da Bahia, e o Núcleo de Acessibilidade e Inclusão Acadêmica da Universidade Federal do Sul e Sudeste do Pará, alinhados à Política Nacional de Educação Especial na perspectiva da Educação Inclusiva. A Universidade Federal do Recôncavo da Bahia oferece o curso de bacharelado em Engenharia de Tecnologia Assistiva e Acessibilidade com o objetivo de promover a funcionalidade relacionada à atividade e à participação de pessoas com deficiência, incapacidades ou com mobilidade reduzida, visando à sua autonomia, independência, qualidade de vida e inclusão social.

O Quadro 1 apresenta as tecnologias mais promissoras para implementação pelas empresas que oferecem produtos e serviços para pessoa com deficiência visual, sendo o Brasil o país com o maior número de registros. 
Quadro 1 - Inovações promissoras e com grande potencial de mercado para atender às pessoas com deficiência visual

\begin{tabular}{|c|c|c|c|}
\hline Título da TeCnologia & Proteção & $\begin{array}{l}\text { ANo do } \\
\text { DePósito }\end{array}$ & Número de Registro \\
\hline $\begin{array}{l}\text { Dispositivo portátil ótico-mecânico para } \\
\text { transcrição de textos em Braille e áudio }\end{array}$ & Patente & 2014 & BR 1020120164329A2 \\
\hline $\begin{array}{l}\text { Terminal de autoatendimento com recursos } \\
\text { de acessibilidade e usabilidade para } \\
\text { pessoas com baixa visão ou idosas }\end{array}$ & Patente & 2009 & BR 1020130177750A2 \\
\hline Speakcode & $\begin{array}{l}\text { Programa de } \\
\text { computador }\end{array}$ & 2018 & BR512018052065-0 \\
\hline $\begin{array}{l}\text { Métodos e sistemas para gerar automaticamente } \\
\text { descrições de acessibilidade de visualização de dados }\end{array}$ & $\begin{array}{l}\text { Programa de } \\
\text { computador }\end{array}$ & 2017 & US2017337220 \\
\hline $\begin{array}{l}\text { Método para acessibilidade de imagens digitais } \\
\text { em tempo real a pessoas com deficiência visual }\end{array}$ & Patente & 2015 & WO2015072823 \\
\hline $\begin{array}{l}\text { Detecção de acessibilidade de propriedades } \\
\text { de conteúdo por meio de interações táteis }\end{array}$ & $\begin{array}{l}\text { Programa de } \\
\text { computador }\end{array}$ & 2017 & CN106415446 \\
\hline $\begin{array}{l}\text { Aparelho para gerenciamento multimídia de } \\
\text { dispositivos de computação para pessoas } \\
\text { cegas ou com deficiência visual }\end{array}$ & Patente & 2018 & BR112018073168-4A2 \\
\hline Leitor para rótulo de embalagem & Patente & 2008 & PI 0802475-8A2 \\
\hline $\begin{array}{l}\text { Sistema de identificação de produto } \\
\text { embalado para uso em lojas }\end{array}$ & Patente & 2006 & ES20040002861 \\
\hline Barcode Speak & $\begin{array}{l}\text { Programa de } \\
\text { computador }\end{array}$ & 2020 & BR512020001689-8 \\
\hline
\end{tabular}

Fonte: INPI (2020)

A Figura 2 mostra os depositantes das nove tecnologias relacionadas com o escopo da pesquisa. Entre os quatro registros identificados no INPI, três foram de titularidade de universidades ou de institutos tecnológicos brasileiros. O Dispositivo portátil ótico-mecânico para transcrição de textos em Braille e em áudio foi desenvolvido pela Fundação Centros de Referência em Tecnologias Inovadoras (Certi), vinculada à Universidade Federal de Santa Catarina. A Fundação Certi é uma instituição sem fins lucrativos que atua em pesquisa, desenvolvimento e serviços tecnológicos para o mercado de forma geral. $\mathrm{O}$ dispositivo permite ao estudante ler arquivos eletrônicos de texto tanto em Braille como em áudio ou simultaneamente em áudio e em Braille. O dispositivo também permite escrever textos e editar arquivos no teclado Braille embutido ou em um teclado normal conectado por USB, além de capturar texto impresso, e converte em arquivo de texto para ser lido em Braille ou em áudio. Embora seja uma importante ferramenta para tradução de textos, o dispositivo não apresenta outras funcionalidades que possibilitem à pessoa com deficiência ter maior independência e liberdade de escolha. 
Figura 2 - Empresas depositantes com registros de patentes e programas de computador diretamente relacionados ao tema
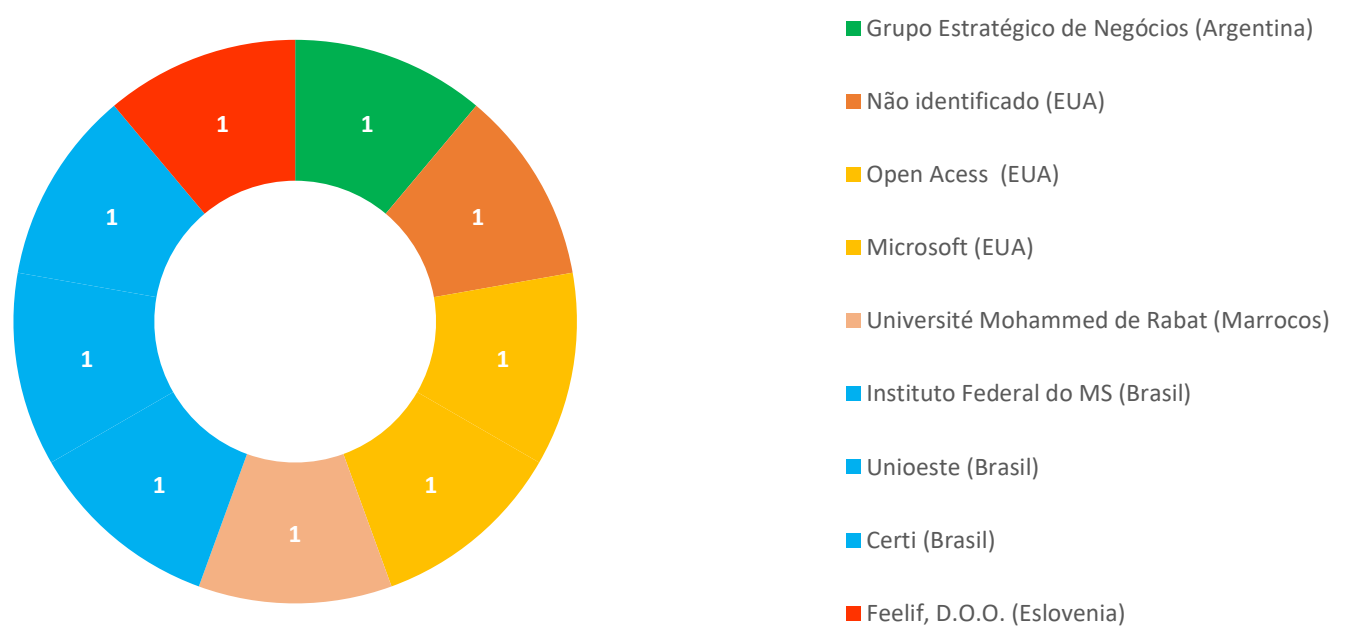

Fonte: Elaborado pelos autores deste artigo (2020)

Registrado pela Universidade Estadual do Oeste do Paraná, o Terminal de autoatendimento com recursos de acessibilidade e de usabilidade para pessoas com baixa visão ou idosas disponibiliza um conjunto de mecanismos que garante o acesso a informações de interesse público em bancos, agências governamentais, quiosques turísticos e também em aeroportos, com baixo custo. Trata-se de "uma interface multimodal, simultânea e integrada, composta por três eixos de interação": visual, obtido por meio de um ampliador de tela; auditivo, através da implementação de um leitor de tela; e tátil, utilizada via mouse. Por se tratar de uma tecnologia disponível apenas em locais específicos, esse terminal acaba limitando o acesso das pessoas com deficiência ao serviço de maneira irrestrita.

O Instituto Federal de Educação, Ciência e Tecnologia de Mato Grosso do Sul é o titular do Speakcode. Esse aplicativo pode ser usado para "leitura e transcrição do conteúdo de códigos QR em áudio", por meio do qual o usuário com deficiência visual pode identificar "produtos e objetos previamente marcados, facilitando a realização de tarefas cotidianas e profissionais". A descrição mais detalhada do aplicativo foi publicada na Revista Brasileira da Educação Profissional e Tecnológica em 2020, com o título "Speakcode: uma ferramenta de acessibilidade para pessoas com deficiência visual” (PACHE et al., 2020).

A empresa americana Open Access Tech INC desenvolveu os Métodos e os sistemas para gerar automaticamente descrições de acessibilidade de visualização de dados, com a finalidade de analisar objeto ou imagem por meio de dispositivo ligado ao computador, descrevendo-o por meio de audiodescrição. A Open Access é uma instituição dedicada a auxiliar empresas na criação de bibliotecas de documentos digitais voltadas para pessoas com deficiências visual ou cognitiva.

A Université Mohammed de Rabat do Marrocos é a titular do Método para acessibilidade de imagens digitais em tempo real a pessoas com deficiência visual. Essa invenção permite traduzir automaticamente o conteúdo semântico da imagem científica em um formato de texto padronizado em tempo real. O objetivo do equipamento é tornar a imagem acessível às pessoas com deficiência visual, por meio de tecnologias assistivas. 
Registrada pela Microsoft, a Detecção de acessibilidade de propriedades de conteúdo por meio de interações táteis utiliza recursos, como calor, vibrações ou cargas estáticas, para gerar interação entre usuário com deficiência visual e a tela do computador. O usuário utiliza o toque para compreender mais facilmente a formatação e a estrutura de um documento, além de criar documentos formatados e estruturados de forma consistente.

O Aparelho para gerenciamento multimídia de dispositivos de computação para pessoas cegas ou com deficiência visual foi depositado pela empresa eslovena Feelif, D.O.O, que tem foco em sistemas de informação exclusivamente voltados para a inclusão de pessoas com deficiência visual a informações em formato digital, com conteúdo educacional digital multissensorial, jogos e aplicativos. É um aparelho para gestão multimídia de dispositivos de computação, que permite que pessoas com deficiência visual usem computadores desktop, laptops, tablets PCs, computadores portáteis, telefones inteligentes e todos os tipos de dispositivos de computação que utilizam tela sensível ao toque para se comunicar com os usuários.

O Leitor para Rótulo de embalagem permite que o consumidor leia com clareza todas as informações contidas nos rótulos das embalagens, a partir da fixação de uma lente de aumento junto ao produto. Essa invenção tem a finalidade de melhorar a leitura de informações, inclusive para pessoas com perfeita visão. Entretanto, não amplia sua funcionalidade para cegos, limitando-se a pessoas com baixa visão.

Grupo Estratégico de Negócios da Argentina é o titular do Sistema de identificação de produto embalado para uso em lojas, que tem o objetivo de realizar leitura de textos e de caracteres dispostos na embalagem e transmiti-los para uma impressora que os transforma em textos em Braille. Nessa invenção, as etiquetas são impressas em código Braille contendo o nome genérico de composição farmacêutica ou medicamento adquirido e a data de validade do produto adquirido. A impressão em Braille em embalagens acartonadas tem sido uma alternativa adotada por algumas empresas para torná-las mais acessíveis, como Natura, Sadia, Nestlé, Melitta, Nutri e produtos do Grupo Pão de Açúcar (MOLINA, 2015). No entanto, o espaço disponível para imprimir as informações necessárias nas embalagens - nome do produto, data de validade, informações nutricionais, ingredientes e contatos do Serviço de Atendimento ao Consumidor - não é suficiente. Dessa forma, informações relevantes podem não ficar acessíveis às pessoas com deficiência visual.

Embora não tenha registro identificado no IPNI ou no Espacenet ${ }^{\circledR}$, o leitor de textos em Braille denominado "Blindl-e" foi desenvolvido por alunos do curso de Eletrônica do Centro Federal de Educação Tecnológica de Minas Gerais e apresentado em 2019 na London International Youth Science Forum. A inovação tem por objetivo transformar textos digitais em formato txt para o padrão Braille, com baixo custo de produção (MARQUES, 2018).

Soares et al. (2020) observaram que a ferramenta de acessibilidade em embalagens alimentícias e de rotulagem nutricional mais utilizada é o sistema tátil de código Braille, a partir da análise de artigos científicos publicados em periódicos nacionais e internacionais entre os anos de 2005 e 2019. Para os autores, ainda há grande limitação de acessibilidade de rótulos e embalagens, pois o sistema Braille geralmente não é acessível para todas as pessoas com deficiência visual, além disso, muitas embalagens não são adaptáveis para esse tipo de linguagem, 
devido ao tamanho e à composição do material (SOARES et al., 2020). Segundo o Censo 2010, há mais de 6,5 milhões de pessoas com deficiência visual no Brasil, sendo 582 mil cegas e 6 milhões com baixa visão, mas estima-se que apenas $10 \%$ dessas pessoas sejam alfabetizados em Braille (IBGE, 2010).

A inovação mais recentemente depositada pela Universidade Federal do Sul e Sudeste do Pará foi o Aplicativo de descrição para leitura de composição (Barcode Speak), que tem como finalidade consultar a descrição de itens com código de barras ou QR Code, por meio das interfaces de comunicação com o banco de dados de organizações públicas e/ou privadas, utilizando a câmera de smartphones ou similares para descrever as informações por meio do sintetizador de voz do aparelho, além disso, é possível escolher produtos para compra via carrinho virtual. Esse programa vai ao encontro das premissas da Lei Brasileira de Inclusão da Pessoa com Deficiência, que aponta a tecnologia assistiva como promotora da autonomia, independência, qualidade de vida e inclusão social de cegos e de pessoas com deficiência visual (BRASIL, 2015).

Os dados apresentados mostram a necessidade de serem desenvolvidas novas tecnologias e invenções que atendam à demanda da pessoa com deficiência visual. Para Soares et al. (2020), leitores eletrônicos de etiquetas podem ser uma alternativa promissora para a pessoa com deficiência visual acessar informações sobre produtos. Neste trabalho, dois programas de computador foram identificados como potenciais ferramentas inovadoras de acessibilidade (Speakcode e Barcode Speak) que podem ser aplicadas no dia a dia da pessoa com deficiência visual, utilizando a tecnologia de audiodescrição.

As recentes discussões sobre inclusão e acessibilidade têm criado um ambiente favorável para o desenvolvimento de novas tecnologias assistivas que permitam a interação de pessoas com deficiência visual com o mercado, bem como facilitem a rotina e melhorem a qualidade de vida dessas pessoas. Essas discussões possuem amparo legal, como o Código de Defesa do Consumidor, que assegura às pessoas com deficiência visual o direito a informações corretas e claras sobre os diferentes produtos e serviços ofertados, por quaisquer meios de comunicação empregados, inclusive em ambiente virtual, com objetivo de harmonizar os interesses dos participantes das relações e consumo, buscando o equilíbrio nas relações entre consumidores e fornecedores (BRASIL, 1990).

Nas redes sociais, existem movimentos consolidados que promovem o debate sobre os direitos adquiridos por esse público, sobretudo o relacionado a produtos com pouca ou nenhuma acessibilidade, como o canal "Reclame Acessibilidade", que conta com perfil oficial no Facebook e no YouTube, dando voz a pessoas com deficiência que não estão satisfeitas com a pouca ou nenhuma acessibilidade presente nos bens, produtos e serviços consumidos. Por meio de vídeos, cartas e áudios, as pessoas com deficiência comprovam que os insumos e os serviços ofertados estão aquém das suas necessidades.

Algumas empresas têm demonstrado preocupação com o uso de tecnologias acessíveis nos seus produtos, como o código Braille e o serviço de acessibilidade por meio de seus canais de venda e de atendimento ao cliente. Entretanto, ainda estão muito longe de promover as condições necessárias de atendimento ao cliente com deficiência, principalmente visual. 


\section{Considerações Finais}

A acessibilidade promove condições de integração social e melhora a qualidade de vida das pessoas com deficiência, permitindo que essa parcela da população possa interagir com o ambiente que a cerca de maneira autossuficiente, como resultado de sensibilização e de conscientização junto à sociedade e da convivência na diversidade humana.

Este estudo prospectivo aponta que ainda há um vasto campo a ser explorado quando se avaliam os produtos tecnológicos disponíveis para atender às necessidades de pessoas com deficiência visual. Entretanto, foi possível identificar patentes e programas de computador com grande potencial inovador, inclusive os aplicativos podem atender à demanda de embalagens e de rótulos.

As empresas que adotarem as novas tecnologias assistivas de comunicação inclusiva terão um diferencial competitivo, sendo que este agrega valor intangível em reputação para as marcas vinculadas, além de contribuir, de fato, para o público com deficiência visual no processo de consumo de produtos, como os alimentícios.

Embora seja cada vez mais ativa e com elevado potencial de consumo, foi possível observar que as pessoas com deficiência compõem uma parte do mercado ainda pouco explorada, mesmo diante de um nicho crescente de mercado e com avanços relevantes para a sociedade nas discussões sobre diversidade e inclusão.

\section{Perspectivas Futuras}

As demandas sociais sobre direitos a condições adequadas de acessibilidade para pessoas com deficiência têm sido a mola propulsora para mudança do mercado e de governança, possibilitando a construção de novas tecnologias para reduzir e corrigir as profundas desvantagens sociais. A tendência é o uso de tecnologias assistivas, como a audiodescrição para leitura de código QR, em todos os produtos comercializados, promovendo a participação da pessoa com deficiência visual na vida econômica, social e cultural de forma mais efetiva.

\section{Referências}

ABNT - ASSOCIAÇÃO BRASILEIRA DE NORMAS TÉCNICAS. NBR 15599/2008. Acessibilidade: comunicação na prestação de serviços. Rio de Janeiro: ABNT, 2008.

AUDIO DESCRIPTION COALITION. Diretrizes para Audiodescrição e Código de Conduta Profissional para Áudio-descritores. Trad. de P. Vieira. Revista Brasileira de Tradução Visual, [s.l.], v. 4, 2010. Disponível em: http://www.rbtv.associadosdainclusao.com.br/. Acesso em: 20 nov. 2019.

BRASIL. Constituição da República Federativa do Brasil. Brasília, DF: Presidência da República; Subchefia para Assuntos Jurídicos; Senado Federal, 1988.

BRASIL. Decreto n. 3.298/1999. Dispõe sobre a Política Nacional para a Integração da Pessoa Portadora de Deficiência. Brasília, DF: Presidência da República; Casa Civil, 1999. 
BRASIL. Decreto n. 5.296/2004. Brasília, DF: Presidência da República; Casa Civil; Subchefia para Assuntos Jurídicos, 2004.

BRASIL. Decreto Legislativo n. 186/2008. Aprova o texto da Convenção sobre os Direitos das Pessoas com Deficiência e de seu Protocolo Facultativo, assinados em Nova Iorque. Brasília, DF, 2008.

BRASIL. Decreto n. 6.949/2009. Brasília, DF: Presidência da República; Casa Civil, 2009.

BRASIL. Lei n. 9.610/1998. Altera, atualiza e consolida a legislação sobre direitos autorais e dá outras providências. Brasília, DF: Presidência da República; Casa Civil; Subchefia para Assuntos Jurídicos, 1998.

BRASIL. Lei n. 13.146/2015. Institui a Lei Brasileira de Inclusão da Pessoa com Deficiência (Estatuto da Pessoa com Deficiência). Brasília, DF: Presidência da República; Secretaria-Geral; Subchefia Para Assuntos Jurídicos, 2015.

BRASIL. Lei n. 10.098/2000. Brasília, DF: Portaria Ministerial; MEC 3.284/03, 2000.

BRASIL. Lei n. 9.279/1996. Regula direitos e obrigações relativos à propriedade industrial. Diário Oficial [da] República Federativa do Brasil, Brasília, DF, 14 maio 1996. Disponível em: http:// www.planalto.gov.br/ccivil_03/Leis/L9279.htm. Acesso em: 31 jul. 2019.

BRASIL. Lei n. 8.078/1990. Dispõe sobre proteção do consumidor e dá outras providências. Brasília, DF: Presidência da República; Secretaria-Geral/Subchefia para Assuntos Jurídicos, 1990.

CAMPÊLO, R. A. et al. Inclusão digital de Deficientes Visuais: o uso da Tecnologia Assistiva em Redes Sociais online e Celulares. Computer on the Beach, [s.l.], p. 109-118, 2011. Disponível em: https://siaiap32.univali.br/seer/index.php/acotb/article/view/6329. Acesso em: 4 fev. 2020.

DAMASCENA, E. O. Elementos Sensoriais em Supermercados: uma Investigação na Perspectiva Transformativa do Consumidor Junto a Pessoas com Deficiência Visual. 2013. 122f. Dissertação (Mestrado) - Universidade Federal de Pernambuco, Recife, 2013.

EUROPEAN PATENT OFFICE (Espacenet). Portal virtual. 2017. Disponível em: https://worldwide. espacenet.com. Acesso em: 30 set. 2019.

FOGAÇA, A. Dica: como adaptar smartphones para deficientes visuais? Showmetech, São Paulo, p. 1, 17, nov. 2016. Disponível em: https://www.showmetech.com.br/como-smartphones-funcionampara-deficientes-visuais/. Acesso em: 15 out. 2019.

FRANCO, E. P. C. A importância da pesquisa acadêmica para o estabelecimento de normas de audiodescrição no Brasil. Revista Brasileira de Tradução Visual (RBTV), [s.l.], v. 3, 2010. Disponível em: http://www.rbtv. associadosdainclusao.com.br. Acesso: 10 dez. 2019.

FRANCO, E. P. C. Revelando a deficiência e a eficiência, o ver e o não ver por meio da pesquisa sobre audiodescrição. [2013]. Disponível em: http://200.156.28.7/Nucleus/media/ common/revista/2013/RBCEE3/Nossos_Meios_RBC_RevEE3Out2013_Texto_6.docx. Acesso em: 12 out. 2019.

HERSH, M. A.; JOHNSON, M. A. Assistive technology for visually impaired and blind people. Springer, [s.l.], p. 752, 2010. 
IBGE - INSTITUTO BRASILEIRO DE GEOGRAFIA E ESTATÍSTICA. Censo demográfico: características gerais da população, religião e pessoas com deficiência. 2010. Acesso em: https:// biblioteca.ibge.gov.br/visualizacao/periodicos/94/cd_2010_religiao_deficiencia.pdf. Disponível em: 10 mar. 2021.

INPI - INSTITUTO NACIONAL DA PROPRIEDADE INDUSTRIAL. Portal virtual. 2020. Disponível em: http://www.inpi.gov.br/. Acesso em: 24 nov. 2019.

MANDUCHI, R.; KURNIAWAN, S.; BAGHERINIA, H. Blind guidance using mobile computer vision: a usability study. Proceedings of the 12th, [s.l.], p. 1-3, 2010.

MARQUES, L. Alunos de Minas Gerais criam leitor em braile de baixo custo. 2018. Disponível em: http://portal.mec.gov.br/component/tags/tag/52541. Acesso em: 15 out. 2020.

MIDIACE - ASSOCIAÇÃO MÍDIA ACESSÍVEL. Audiodescrição. [2020]. Disponível em: http:// www.midiace.com.br/index.php/audiodescricao\#: :text=A\%20audiodescri\%C3\%A7\%C3\%A3o\%20 \%C3\%A9\%20um\%20recurso,ao\%20p\%C3\%BAblico\%20de\%20produtos\%20 audiovisuais.\&text $=\% \mathrm{C} 3 \% 89 \% 2 \mathrm{C} \% 20$ portanto $\% 2 \mathrm{C} \% 20 \mathrm{tamb} \% \mathrm{C} 3 \% \mathrm{~A} 9 \mathrm{~m} \% 20$ definido $\% 20$ como,transposto\%20para\%20o\%20signo\%20verbal. Acesso em: 28 set. 2020.

MOLINA, L. Acessibilidade na prática. Consumidores com deficiência visual e os rótulos em Braille. 2015. Disponível em: http://www.acessibilidadenapratica.com.br/textos/consumidores-comdeficienciavisual-e-os-rotulos-em-braille/. Acesso em: 3 mar. 2021.

MONTEIRO, J. L. Os desafios dos cegos nos espaços sociais: um olhar sobre a acessibilidade. 2012. Disponível em: http://www.ucs.br/etc/conferencias/index.php/anpedsul/9anpedsul/paper/ viewFile/1081/649. Acesso em: 18 jun. 2019.

MOTTA, L. M. V. M. M.; ROMEU FILHO, P. (org.). Audiodescrição: transformando imagens em palavras. São Paulo: Secretaria de Estado dos Direitos da Pessoa com Deficiência, 2010.

NUNES, S. S.; LOMÔNACO, J. F. B. Desenvolvimento de conceitos em cegos congênitos: caminhos de aquisição do conhecimento. Revista Semestral da Associação Brasileira de Psicologia Escolar e Educacional, [s.l.], v. 12, n. 1, p. 119-138, 2008.

OLIVEIRA, C. B.; NETO, P. C. S. Acessibilidade web em dispositivos móveis: uma proposta de métrica para o desenvolvimento de conteúdo web móvel acessível a deficientes visuais. Revista Profiscientia, [s.l.], p. 4-5, 2019.

OLOFSSON, S. Designing interfaces for the visually impaired: contextual information and analysis of user needs. 2017. Disponível em: https:/www.diva-portal.org/smash/get/diva2:1179505/ FULLTEXT01.pdf. Acesso em: 10 mar. 2021.

OMS - ORGANIZAÇÃO MUNDIAL DA SAÚDE. Classificação Estatística Internacional de Doenças e Problemas Relacionadas à Saúde. 10. ed. São Paulo: EDUSP, 2003.

OMS - ORGANIZAÇÃO MUNDIAL DA SAÚDE. World Report on Vision. Suíça: OMS, 2019. 180p.

PACHE, M. C. B. et al. Speakcode: uma ferramenta de acessibilidade para pessoas com deficiência visual. Revista Brasileira da Educação Profissional e Tecnológica, Mato Grosso do Sul, março de 2020.

QUINTELLA, C. M.; MATA, A. M. T.; LIMA, L. C. P. Overview of bioremediation with technology assessment and emphasis on fungal bioremediation of oil contaminated soils. Journal of Environmental Management, [s.l.], v. 241, p. 156-166, 2019. 
RIBEIRO, Núbia Moura (org.). Prospecção tecnológica. Salvador, BA: IFBA, 2018. 194p.

(PROFNIT, Prospecção tecnológica. v. 1. [Recurso eletrônico on-line]). Disponível em: https://www. profnit.org.br/wp-content/uploads/2018/08/PROFNIT-Serie-Prospeccao-Tecnologica-Volume-1-1.pdf. Acesso em: 12 ago. 2021.

RELATÓRIO MUNDIAL SOBRE A DEFICIÊNCIA/WORLD HEALTH ORGANIZATION. The World Bank. Tradução Lexicus Serviços Linguísticos. São Paulo: SEDPcD, 2012. 334 p.

SASSAKI, R. K. Inclusão: acessibilidade no lazer, trabalho e educação. Revista Nacional de Reabilitação (Reação), São Paulo, ano XII, p. 10-16, 2009.

SOARES, P. T. S. et al. Contribuição de embalagens alimentícias e rotulagem nutricional para a autonomia e inclusão social de pessoas com deficiência visual: um panorama atual do mercado.

Alimentos: Ciência, Tecnologia e Meio Ambiente, [s.l.], v. 1, n. 3, p. 63-78, 2020.

VANZIN, T. Mídias do conhecimento: um retrato da audiodescrição no Brasil. Revista de Ciência da Informação, [s.l.], v. 11, n. 6, dez. 2010. Disponível em: http://www.dgz.org.br/dez10/Art_05. htm. Acesso em: 13 nov. 2019.

VENTURA, L. A. S. Dell investe em tecnologia assistiva. [2019]. Disponível em: https://brasil. estadao.com.br/blogs/vencer-limites/dell-investe-em-tecnologia-assistiva/. Acesso em: 2 fev. 2020.

VILLELA, Flávia. Agência Brasil. IBGE: 6,2\% da população têm algum tipo de deficiência. 2015. Disponível em: http://agenciabrasil.ebc.com.br/geral/noticia/2015-08/ibge-62-da-populacao-temalgum-tipo-de-deficiencia. Acesso 13 mar. 2021.

VIEIRA, P. A. M.; LIMA, F. J. A Teoria na Prática: audiodescrição, uma inovação no material didático. Revista Brasileira de Tradução Visual, [s.l.], 2010.

\section{Sobre os Autores}

\section{Adriana Monteiro da Cunha}

E-mail: montedrica@gmail.com ORCID: http://orcid.org/0000-0003-4503-1727

Mestre em Propriedade Intelectual e Transferência de Tecnologia para a Inovação pelo Programa de Pós-Graduação em Propriedade Intelectual e Transferência de Tecnologia para a Inovação (Profnit) da Universidade Federal do Sul e Sudeste do Pará (Unifesspa) em 2021.

Endereço profissional: Rua Prof. Nelson Ribeiro, n. 4.223, Telégrafo, Belém, PA. CEP: 66113-075.

\section{Sidnei Cerqueira dos Santos}

E-mail: sidnei.cerqueiradossantos@gmail.com

ORCID: http://orcid.org/0000-0003-1169-256X

Doutor em Biotecnologia pelo Programa de Doutorado em Biotecnologia - Rede Nordeste de Biotecnologia (RENORBIO) da Universidade Estadual do Ceará (UECE) em 2013.

Endereço profissional: Avenida dos Ipês, s/n, Cidade Jardim, Marabá, PA. CEP: 68500-000. 